\title{
Using infrared radiation in preparation of feed for farm livestock
}

\author{
Sergei V. Shchitov, Ekaterina I. Reshetnik, Vyacheslav G. Evdokimov, Lyubov I. Perepelkina, \\ Zoya F. Krivuca, Yulia R. Samarina, Evgeniy E. Kuznetsov, Natalia A. Kapustina \\ Far Eastern State Agrarian University, Russia
}

\begin{tabular}{l}
\hline \hline Article Info \\
\hline Article history: \\
Received Aug 6, 2018 \\
Revised Nov 19, 2018 \\
Accepted Mar 3, 2019 \\
\hline Keywords: \\
Drying unit \\
Feed ration \\
Infrared radiation \\
Nutritional properties \\
Processing line
\end{tabular}

\begin{abstract}
The article in hand describes a processing line for preparation of feed for farm livestock and the design of an infrared drying unit integrated into this line. The main objective of this study is to find ways to provide a full-value feeding of farm animals throughout the calendar year. At present, there are various methods for preserving feed proposed with the aim of providing a full-fledged diet. However, following the recommendations for feed storage according to the recommended conditions, as a rule, results in high losses of its total weight and nutritional properties due to a long winter period with low-temperature regimes, typical of the Amur Region of Russia. This article presents the results of the study of a prospective processing line for the preparation of feed for long-term storage, which ensures the preservation of their basic nutritional properties, with an integrated infrared drying unit.
\end{abstract}

Copyright $(2019$ Institute of Advanced Engineering and Science. All rights reserved.

\section{Corresponding Author:}

Sergei V. Shchitov,

Far Eastern State Agrarian University,

Blagoveshchensk, Russia.

Email: aleksandrovna.lg@mail.ru

\section{INTRODUCTION}

The analysis of the existing and applied feed rations shows that the farms of the Amur Region use the following livestock feeds: hay, silage, tuberous roots, cucurbits crops (e. g. pumpkin and zucchini) and grain (in various forms) [1]. These types of feeds provide for a full-fledged diet of farm animals during the calendar year. At the same time, it should be noted that in case of using the first three types of feed in winter, the main difficulty is their removal from storage and transport to the feeding areas.

According to some studies, the loss of feed and nutrients can be up to $25 . .30 \%$, which, in turn, has a significant impact on the production unit cost [2]. Therefore, as of today, the issue of preparing feeds and ensuring a full-fledged ration for farm livestock is particularly relevant for regions with low air temperatures in the winter.

Under such conditions, the most efficient method of preparing feed in summer and autumn is drying. One of the main parameters for this method of feed storage is moisture content, which, depending on the type of feed, should be $13 \ldots 20 \%$ [3-4] The processes for preparing feeds for long-term storage by drying differ only in the methods of supplying heat. They are convective heating, conductive heating, heating by thermal radiation, heating by electric currents of high and ultrahigh frequency and sublimation heating. Each of these drying methods has its pros and cons. At present, the most widely applied methods are as follows: convective, sublimation and infrared drying [5-6]. The analysis of known methods shows that the most prospective technique for the Amur Region, given its conditions, is infrared drying [7-8].

This method allows to use up to $100 \%$ of the supplied heat, which is especially important since the cost of energy carriers is quite high. At the same time, it should be noted that the duration of preparation of feeds by the proposed method is much shorter compared to others. This is due to the fact that such a heat input provides for an intensive evaporation process already at a temperature of $40-600^{\circ} \mathrm{C}$, which ultimately 
results in maximum preservation of the nutrient properties of the drying product and minimal heat loss during the heating of the structure [9]. Therefore, the aim of this work is to design a processing line with an integrated infrared drying unit to reduce energy costs of preparing feeds for long-term storage.

According to previous studies [10-11], drying with infrared rays create temperature extremes, which force moisture to move along the heat flow into the material. In addition, it partially evaporates from the surface. The resulting increase in the moisture content gradient, which exceeds the temperature gradient, becomes the reason why the moisture begins to move to the outer surface. Thus, the temperature gradient must be minimized as it has an inhibitory effect on the movement of moisture within the feed material [12-14].

\section{MATERIAL AND METHODS}

One example of using infrared radiation in the preparation of feed for long-term storage is presented in the processing line shown in Figure 1. The application of this line will allow preserving the nutritional properties of the feed and decreasing the energy costs for its preparation significantly. This processing line is designed for large agricultural producers [11]. The layout of the infrared drying unit included in the proposed processing line is shown in Figure 2.

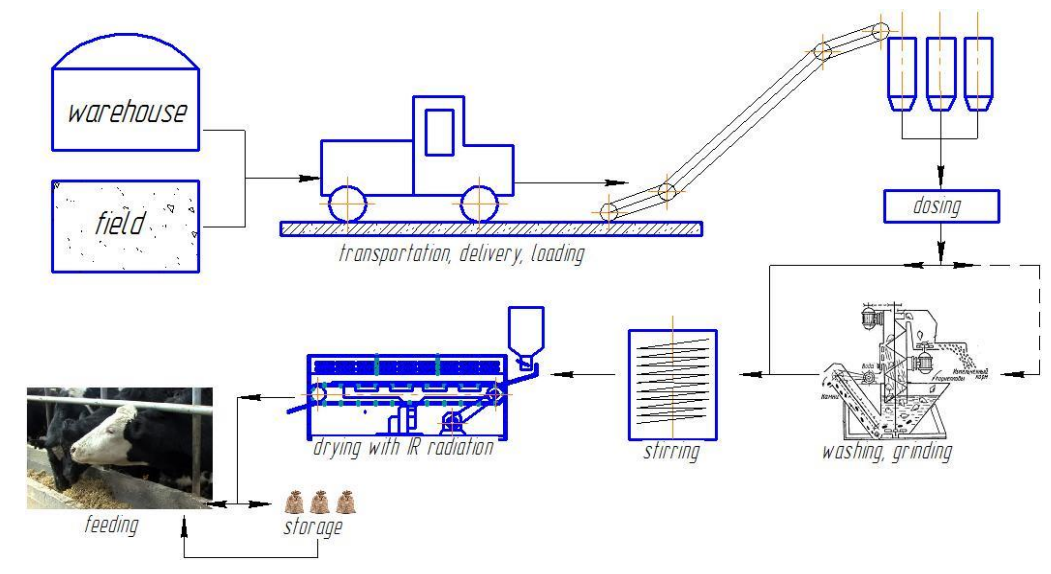

Figure 1. Processing line for feed preparation with an infrared drying unit

From the storage bin 2 the feed material enters the loading tray 1, when it is distributed evenly and sent to the conveyor 5. On entering the working chamber, the feed material is heated under the longwave heating elements 3. Infrared rays heat the product for a few seconds. Simultaneously, 4, through the air duct system, the surface of the feed material is cooled by the airflow generated by the blower 6 . The blowing speed may vary from 10 to $30 \mathrm{~m} / \mathrm{min}$. The cooling of the surface forces the moisture to move to the surface, which increases the drying speed by 2 times. The dried feed material is poured onto the discharge chute 9 and then packed in bags. The conveyor 5 is driven by the electric motor 7 .

The drying process we studied involved feed material with the initial moisture content of $18 \ldots 32 \%$. The prominent feature of the proposed drying unit is the combination of two methods of heat supply-thermal radiation and convection. Simultaneously with heating, the surface of the feed is being cooled by the air flow generated by the blower. At this, the moisture begins to migrate from the core of the feed to its surface, which significantly increases the drying speed $[1,11,15,16]$.

The testing of the drying unit was carried out in accordance with the recommended general and particular methods using specialized programs for mathematical calculation, experimental simulation and regression analysis methods $[11,17]$. The following parameters were measured: the initial and final moisture content of the feed material, the friability of the dried feed, energy consumption, the capacity and power of the unit, the temperature of the drying agent, the air flow rate.

To measure the above parameters, specialized laboratory instruments and apparatus were used. The data obtained during the experiment was processed via known methods of mathematical statistics with the use of information technologies. 

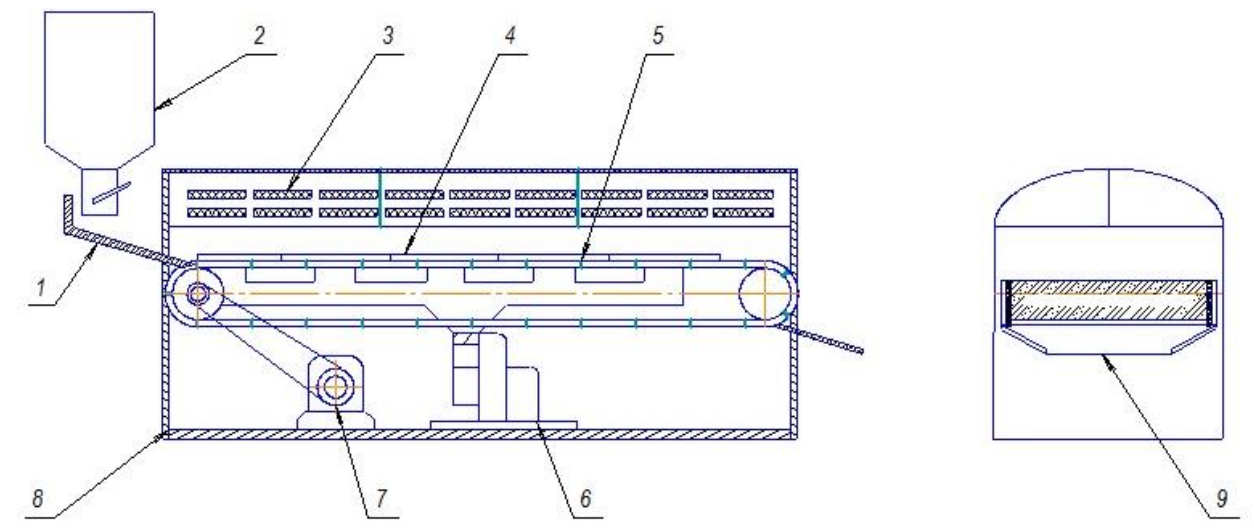

Figure 2. General view of the infrared drying unit: 1) loading tray; 2) storage bin; 3) infrared heating elements; 4) air ducts; 5) conveyer; 6) blower; 7) motor; 8) frame; 9) discharge tray

\section{RESULTS AND DISCUSSION}

Theoretical studies and experimental trials of the processing line with the infrared drying unit conducted at the Far Eastern State Agrarian University (Amur Region, Blagoveshchensk, the Russian Federation) and at the agricultural enterprise "ORTA" verified the validity and appropriateness of the chosen method of preparing feed for long-term storage and justified the necessity for its application in feeding of farm livestock.

Several studies $[1,10,11]$ provide the theoretical justification for the use of infrared radiation in the preparation of feed for long-term storage. As a result of experimental studies, two-dimensional Figures 3 and Figure 4, and three-dimensional in Figures 5 and 6, graphical models of interacting dependences of the main parameters were obtained.

For this, the original regression equations were reduced to equations with two factors, and the remaining interacting values were left at constant levels. The following parameters were set as variation factors: $\mathrm{x} 1$ - heating temperature of the feed material surface $\left(\mathrm{t}^{\circ}\right), 0 \mathrm{C} ; \mathrm{x} 2$ - duration of drying $(\tau)$, min; $\mathrm{x} 3-$ air supply intensity (V), $\mathrm{m} / \mathrm{min} ; \mathrm{x} 4-$ initial moisture content of the feed material (W1), \%. The following parameters were set as final values: Y1 - specific power of the unit (Куд), W/kg and Y2 - final moisture content of the feed material $(\mathrm{W}), \%$.

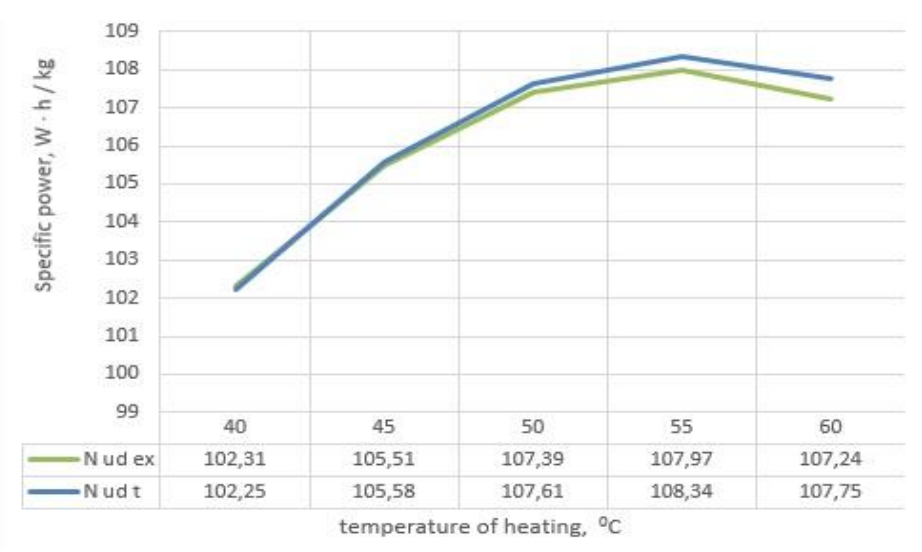

Figure 3. Analytical dependence between specific humidity and heating temperature: theoretical $(=24 \mathrm{~min}$, $\mathrm{V}=10 \mathrm{~m} / \mathrm{min}, \mathrm{W} 1=20 \%$ ) and experimental ( $\tau=23 \mathrm{~min}, \mathrm{~V}=20 \mathrm{~m} / \mathrm{min}, \mathrm{W} 1=21.92 \%)$

The analysis of the relationships presented in Figure 3 proves that an increase in the heating temperature of the surface of the feed material leads to a significant increase in the specific power of the drying unit. Therefore, it is recommended to dry the feed material at temperatures up to $45^{\circ} \mathrm{C}$.

The analysis of the relationships presented in Figure 4 shows that the minimum final humidity is obtained at the minimum or maximum air flow rate. Therefore, it is possible to adjust the air flow rate by 
factoring in the heating temperature and the following parameters: minimum flow rate for minumim possible temperature; maximum flow rate for maximum possible temperature. The bivariate analytical dependencies were built using Microsoft Excel 2010.

To visualize the influence of interacting factors on the drying process of the feed material, we constructed the relevant response surfaces and the cross-sections of the response surface using Mathcad 2000 Professional.

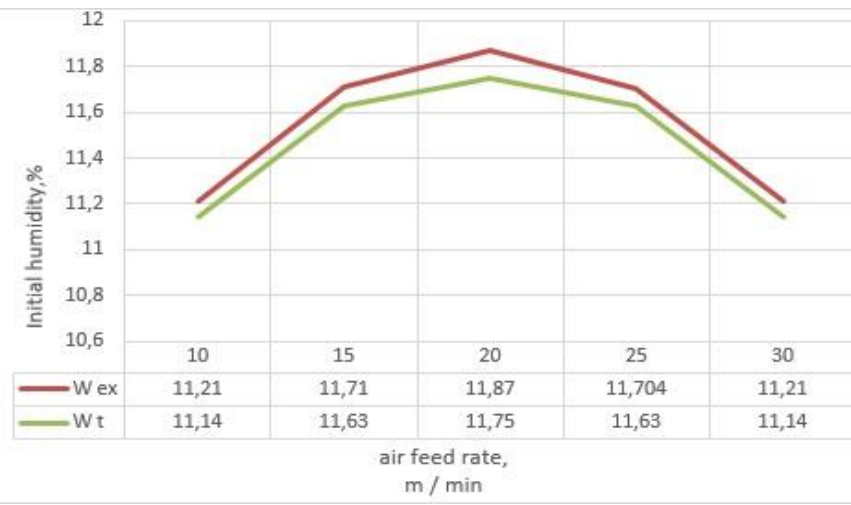

Figure 4. Analytical dependence between final humidity content and air flow rate: theoretical $(\mathrm{t}=400 \mathrm{C}$, $\tau=24 \mathrm{~min}, \mathrm{~W} 1=20 \%)$ and experimental $(\mathrm{t}=430 \mathrm{C}, \tau=23 \mathrm{~min}, \mathrm{~W} 1=21.92 \%)$

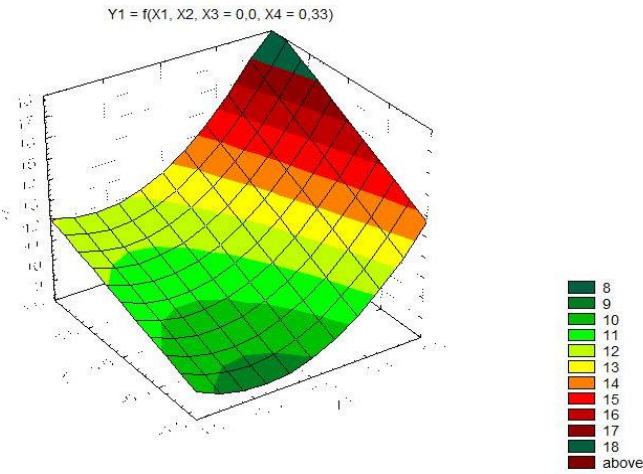

Figure 5. The response surface of the final parameter of the specific power (Nуд) taking into account the air flow rate $(\mathrm{V}=20 \mathrm{~m} / \mathrm{min})$ and the initial moisture content of the feed material $(\mathrm{W} 1=21.98 \%)$

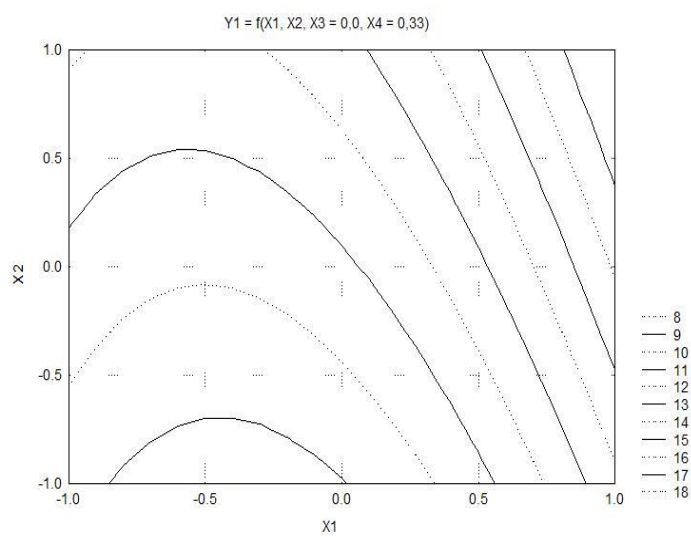

Figure 6. The cross-section of the response surface of the final parameter of the specific power (Nуд) taking into account the air flow rate $(\mathrm{V}=20 \mathrm{~m} / \mathrm{min})$ and the initial moisture content of the feed material $(\mathrm{W} 1=21.98 \%)$ 
The visual analysis of the cross-section of the response surface in Figure 6, helps to establish that with a constant air flow rate $(\mathrm{V}=20 \mathrm{~m} / \mathrm{min})$ and the initial moisture content of the feed material $(\mathrm{W} 1=21.98 \%$ ), the specific power (Nуд) increases. The response surface of the final parameter of the final moisture content of the feed material (W) taking into account the duration of the drying process $(\tau=22 \mathrm{~min})$ and the air flow rate $(\mathrm{V}=20 \mathrm{~m} / \mathrm{min})$ as shown in Figure 7 and The cross-section of the response surface of the final parameter of the final moisture content of the feed material (W) taking into account the duration of the drying process $(\tau=22 \mathrm{~min})$ and the air flow rate $(\mathrm{V}=20 \mathrm{~m} / \mathrm{min})$ as shown in Figure 8.

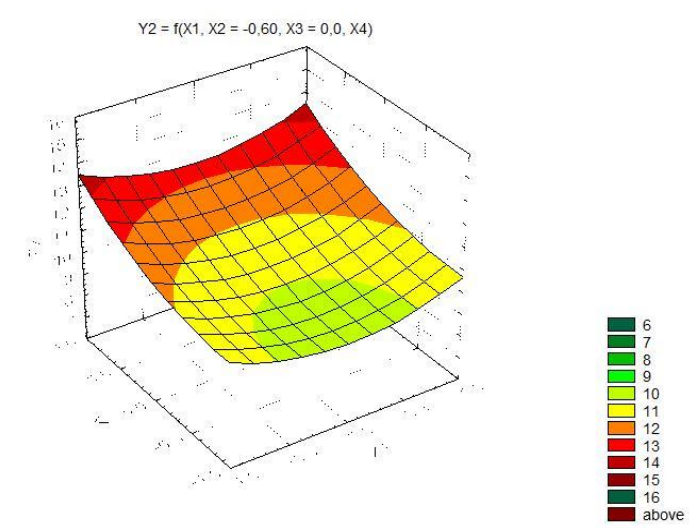

Figure 7. The response surface of the final parameter of the final moisture content of the feed material (W) taking into account the duration of the drying process $(\tau=22 \mathrm{~min})$ and the air flow rate $(\mathrm{V}=20 \mathrm{~m} / \mathrm{min})$

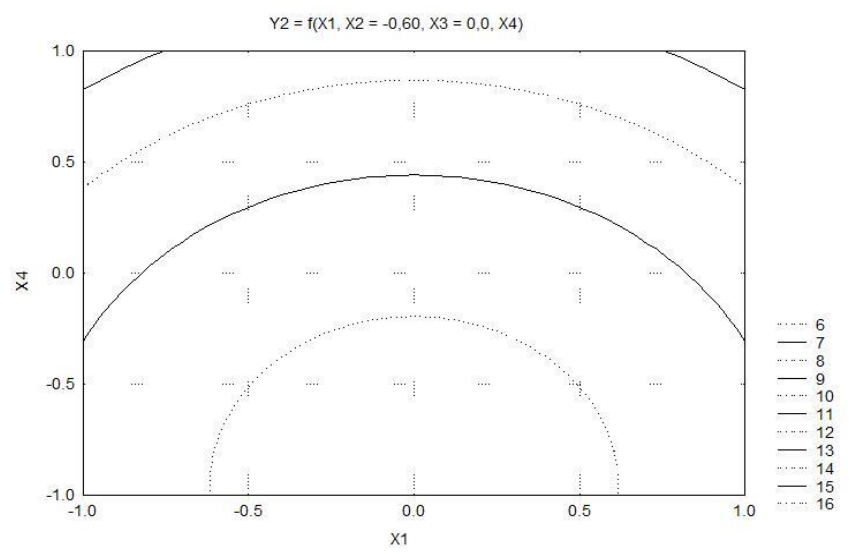

Figure 8. The cross-section of the response surface of the final parameter of the final moisture content of the feed material $(\mathrm{W})$ taking into account the duration of the drying process ( $\tau=22 \mathrm{~min}$ ) and the air flow rate $(\mathrm{V}=20 \mathrm{~m} / \mathrm{min})$

The visual analysis of the response surface cross-sections in Figure 8, establishes that when the duration of the drying process $(\tau=22 \mathrm{~min})$ and the air flow rate $(\mathrm{V}=20 \mathrm{~m} / \mathrm{min})$ are constants, the final moisture content $(\mathrm{W})$ decreases. To confirm the results of the study, we compared several drying methods, similar to the proposed one in main parameters (duration of the process and the heating temperature of the feed product surface). Among them were the convective, sublimation and conductive heating, as well as heating by ultrahigh frequency fields (microwave drying).

The comparison was based on the three main components of the total energy consumption indicators: direct energy costs, energy costs of human labor and those of the equipment as shown in Figures 9-11. The presented data allowed us to conclude that the direct energy costs for the infrared drying are $41.2 \%$ lower than for conductive and microwave drying, $63.1 \%$ lower than for the sublimation drying and $66.7 \%$ lower than those of the convective method.

The analysis of the data in Figure 10 helps to establish that the energy costs of human labor for the infrared drying are $42.2 \%$ lower than for conductive and microwave drying, $63.8 \%$ lower than for sublimation drying and $66.7 \%$ lower than for convective drying. 


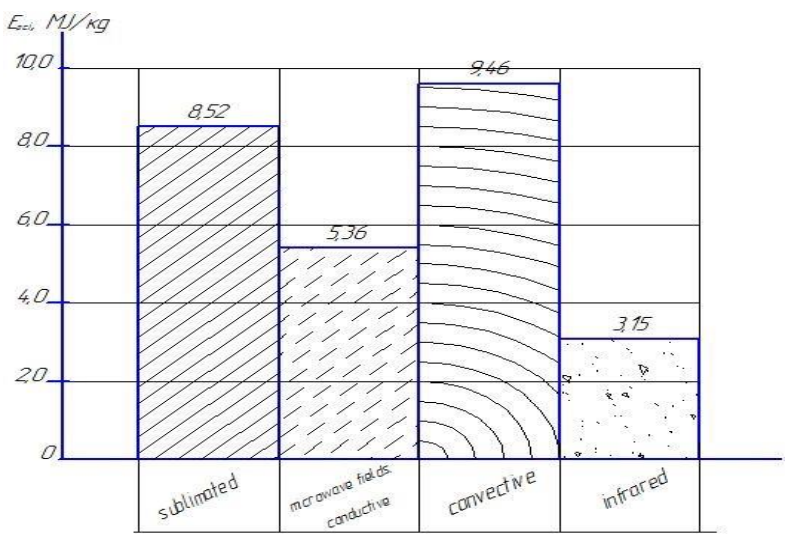

Figure 9. Direct energy costs by different methods of drying

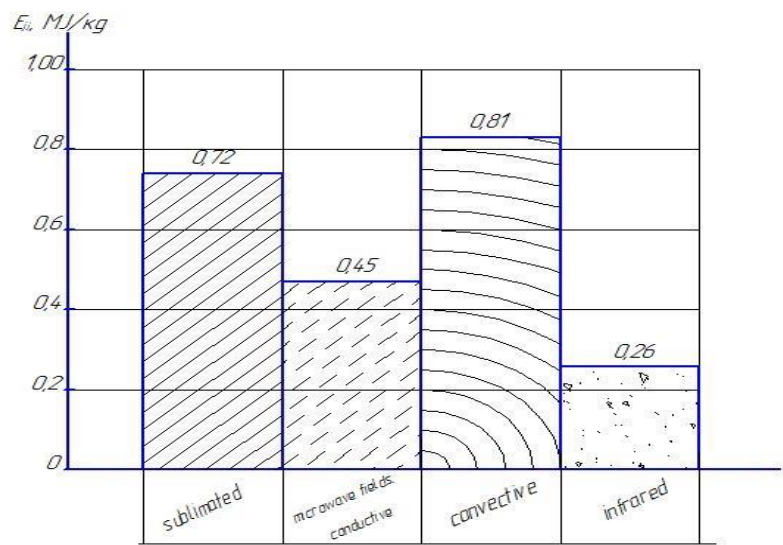

Figure 10. Energy costs of human labor by different methods of drying

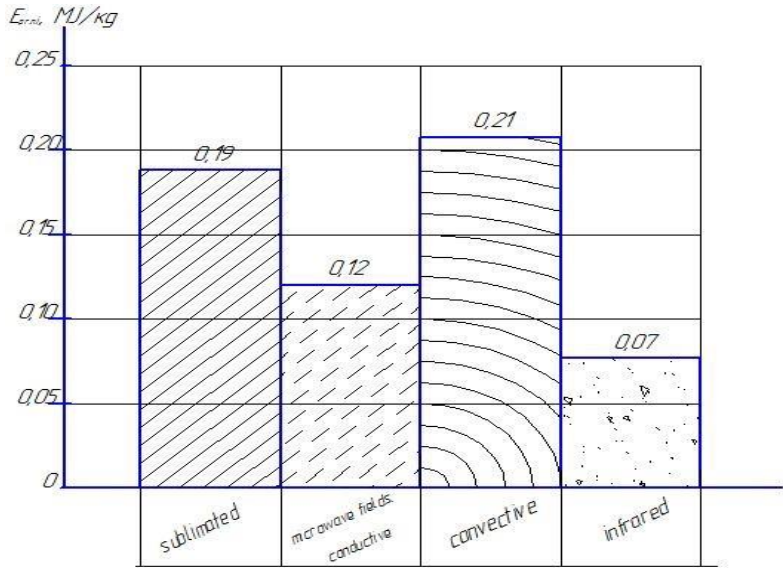

Figure 11. Energy costs of the equipment

The analysis of the data in Figure 11 points to the fact that the energy costs of the equipment for the infrared drying are $41.7 \%$ lower than for conductive and microwave drying, $63.2 \%$ lower than for sublimation drying and $66.7 \%$ lower than for convective drying. Thus, based on the comparative calculations presented above, the authors established that the proposed combined thermal radiation drying method has minimum values for each chosen energy indicators. The conducted fuel and energy evaluation of the existing methods of drying and the proposed combined thermal radiation agent with a convective supply showed that 
during the preparation of the feed material for long-term storage under these conditions, the direct energy costs decreased by $42 \%$, the energy costs of human labor decreased by $43 \%$ and those of the equipment by $41 \%[6,9]$.

The reliability of the obtained data is confirmed by the convergence of the theoretical justifications and experimental parameters determined in the real operating conditions of the combined thermal radiation unit. The comparison of these results with the data previously obtained by the researchers [7], [15]-[17] proves the effectiveness of the proposed solution, which has not been considered by the applied science in its entirety before now.

Based on the foregoing, it can be concluded that the use of a drying unit with infrared radiation technology for preparing feed for long-term storage reduces the time of this preparation, as well as energy costs per production unit. Consequently, the proposed processing line with the infrared drying unit is a highly effective design intended for preparation of feed for long-term storage, that implements original ideas and has an engineering novelty. The results of the studies are successfully used in the feed production technology by several farms, such as "ORTA", "Kovalevskiy V. A." and other agricultural enterprises. The application of the obtained results in the production allowed to decrease the feed preparation time and reduce the energy costs per unit of production.

\section{REFERENCE}

[1] Yu.R. Samarina, A.V. Yakimenko, T.Ya. Samarina, I.V. Bumbar: "Justification of Parameters and Drying Regimes of an Infrared Drying Unit". Machines and Equipment for Villages 12 (2012), 20-23.

[2] V.V. Reymer, Yu.R. Samarina, N.S. Manakov: "The agrarian sector of the economy of the Amur Region: trends and development prospects. Far Eastern Agrarian Bulletin". Journal of Research and Practice. Blagoveshchensk 1 (2017), No. 41, 113-121.

[3] M.N. Khudenko, L.V. Shersnev: "Belt-line production of arable fodder". Saratov: Saratov University Publishing House, 2011, 111.

[4] V.N. Shlapunov: "Arable fodder cropping". 2nd edition, revised and enlarged. Minsk: URADZHAI, 2011, 288.

[5] L. Zhao, H. Mitomo: "Radiation effects on dihydroxypropyl-chitosan". Polym. Degrad.Stab. 93 (2008), No. 8, 1607-1610.

[6] B.A. Semenov: "Engineering experiment in industrial heat engineering, heat power and heat technologies: a tutorial. Electron". Dan. St. Petersburg: Lan., 2013, 384.

[7] A.S. Ginzburg: "The infrared technology in the food industry". Moscow: Food Industry, 2001, 568.

[8] N.I. Lebedev: "Hydraulic machines and volumetric hydraulic drive: a tutorial". Moscow: MSTU. N.E. Bauman, 2002, 232.

[9] Z.Kh. Zamaleev, V.N. Posokhin, V.M. Chefanov: "Fundamentals of hydraulics and heat engineering: a tutorial". Electron. Dan. St. Petersburg: Lan., 2014, 352.

[10] A.V. Yakimenko, V.P. Yakimenko, Yu.R. Samarina: "Wet Pelletizing of Feed Mixes". Rural Mechanization Expert 9 (2007), 36.

[11] Yu.R. Samarina, S. V. Shchitov: "Estimation of Energy Costs for Drying Feed". Machines and Equipment for Villages 7 (2014), 27-28.

[12] A.D. Grigoriev: "Electrodynamics and microwave technology: a textbook". Electron. Dan. St. Petersburg: Lan., 2007, 704.

[13] W. Dongbang, W. Pirompugd, K. Triratanasirichai: "The drying kinetics of chilies using a rotating fluidized bed technique”. Am. J. Applied Sci. 7 (2010), 1599-1606.

[14] G. Cuccurullo, L. Giordano, D. Albanese, L. Cinquanta, M.D. Matteo. "Infrared thermography assisted control for apples microwave drying". J. Food Eng. 112 (2012), 319-325.

[15] S. Jaturonglumlert, T. Kiatsiriroat: "Heat and mass transfer in combined convective and far-infrared drying of fruit leather". J. Food Eng. 100 (2010), 254-260.

[16] S.J. Kowalski, D. Mierzwa: "Numerical analysis of drying kinetics for shrinkable products such as fruits and vegetables". J. Food Eng. 114 (2013), 522-529.

[17] P.C. Williams: "A study of grinders used for sample preparation in laboratory analisis of grains". Cereal Foods World 29 (2004): 770. 